\title{
Phytotoxicity of Rosmarinus officinalis L. and Salvia officinalis L. to Control the Noxious Weed, Panicum turgidum Forssk.
}

\author{
Eman T. E-Kenany* and Amal M. Fakhry \\ Department of Botany and Microbiology, Faculty of Science, \\ Alexandria University, Egypt.
}

\begin{abstract}
D ETRI-DISH experiments were applied to investigate the potential allelopathic effects of cold and hot aqueous extracts of Rosmarinus officinalis and Salvia officinalis on germination percentage, relative germination percentage, and inhibition percentage as well as plumule and radicle lengths of Panicum turgidum. The results indicate that the degree of inhibition on seed germination and growth of the recipient species was largely dependent on the concentration of the extracts of both donor species. The effect was statistically significant at $\mathrm{p} \leq 0.05$ for most treatments. The present study recommends the use of the two donor species for the biocontrol of weeds like Panicum turgidum.
\end{abstract}

Keywords: Allelopathy - Rosmarinus officinalis - Salvia officinalis Panicum turgidum.

Known since ancient times, the phenomenon of allelopathy has recently received greater attention from researchers and farmers worldwide (de Albuquerque et al., 2011). Allelopathy is an interference mechanism by which plants release chemicals which affect other plants; while it has often been proposed as a mechanism for influencing plant populations and communities (Gholami et al., 2011). Increasing attention has been given to the role and potential of allelopathy as a management strategy for crop protection against weeds and other pests.

Incorporating allelopathy into natural and agricultural management systems may reduce the use of herbicides, insecticides, and other pesticides, reducing environment/soil pollution and diminish auto-toxicity hazards (Bajalan et al., 2013a). Meanwhile, there is a great demand for compounds with selective toxicity that can be readily degraded by either the plant or by the soil microorganisms which provide new strategies for maintaining and increasing agricultural production in the future (Inderjit and Keating, 1999).

The two donor species are members of the family Lamiaceae. Rosmarinus officinalis is a flowering plant that grows wildly in Mediterranean countries, southern Europe and in the littoral region through Minor Asia areas (Derwich

*Corresponding author: E-mail: emantahaali@y ahoo.com 
et al., 2011).The essential oil of Rosmarinus officinalis has antioxidant activity (Wang et al., 2008), antibacterial activity (Azfali, 2009), insecticidal toxicity ((Papachristos and Stampoulos, 2004), anti-inflammatory and anti-nociceptive properties (Takaki et al., 2008), antifungal activity (Ozcan and Chalchat, 2008; Pozzatti et al., 2008) and only, in recent years have been commercialized as pest control products (Isman, 2000). Additionally, Salvia officinalis L. has been used for centuries as an herbal remedy. It yields a highly effective essential oil with very sweet overtones and can be used in balms, salves, perfumes, cosmetics and topical applications (Bajalan et al., 2013a). Internally, Salvia officinalis L. essential oil is believed to be of benefit for a multitude of problems, including stress, exhaustion, headaches, insomnia, depression, colds, digestion, flatulence, upset stomach, liver and gallbladder problems, nervousness and etc. (Omid-Beigi, 2009).

A noxious weed is a plant that has adverse effects on or threatens agricultural production (VanGessel, 1995). Panicum turgidum Forssk. (Poaceae) is one of the widely distributed and most drought resistant grasses of the Egyptian desert (Migahid and Elshourbagy, 1961). The success and wide distribution of this plant species indicate its ability to tolerate certain unfavorable conditions (Ismail and Seed, 1983). Accordingly, this species is extremely competitive grass and considered to be one of the most troublesome weed species in cultivated fields. Therefore, the present study aims at assessing the allelopathic effect of two donor species, Rosmarinus officinalis and Salvia officinalis, on seed germination and seedling growth of Panicum turgidum.

\section{Materials and Methods}

\section{Preparation of Donor Species Aqueous Extracts}

Rosmarinus officinalis and Salvia officinalis (donor species) were collected from cultivated fields at El-Sharquia governorate. Healthy leaves from each species were selected carefully, washed in running tap water for removing the surface contaminants and dust and dried at room temperature for three days in the shade. After drying, leaves were powdered using electric blender. Stock aqueous extract was obtained by soaking $50 \mathrm{~g}$ leaf powder in $500 \mathrm{ml}$ of cold and boiled distilled water $(10 \% \mathrm{w} / \mathrm{v})$ at room temperature $\left(20 \pm 2^{\circ} \mathrm{C}\right)$ for $24 \mathrm{hr}$ with occasional shaking. The mixtures were filtered through two layers of cheesecloth and centrifuged for $20 \mathrm{~min}$. at $5000 \mathrm{rpm}$ to remove particulate materials. The purified extracts were kept in the refrigerator at $5^{\circ} \mathrm{C}$ and considered to be the full strength concentration (100\%). Series of subsequent dilutions (5\%, 10\%, $20 \%$ and $40 \%$ ) were prepared in addition to the control (distilled water) and tested for their effects on germination and seedling growth of Panicum turgidum (recipient species).

\section{Germination Bioassay}

Petri-dish experiment was applied to investigate the potential allelopathic effects of cold and hot aqueous extracts of the two donor species on germination percentage (GP), plumule (PL) and radicle (RL) lengths of the recipient species. To accomplish this experiment, 10 seeds of the recipient species were arranged in Egypt. J. Bot., 56, No. 2 (2016) 
$9 \mathrm{~cm}$ diameter Petri-dishes on 2 discs of Whatman No.1 filter paper under normal laboratory conditions with day temperature range of $25-30^{\circ} \mathrm{C}$ and night temperature range $20-25^{\circ} \mathrm{C}$. $5 \mathrm{ml}$ of cold and hot aqueous extracts of the two donor species were separately added daily to three replicates. GP, PL and RL were recorded daily for successive sixteen days. In addition, relative germination percentage (RGP) and inhibition percentage (IP) were calculated from the GP of the allelopathic treated seeds and GP of the control.

\section{Calculations}

Germination percentage (GP)

$\mathrm{GP}=($ number of germinated seeds / total number of seeds $) \times 100$

Relative germination percentage (RGP)

$\mathrm{RGP}=$ (allelopathic/control) $\mathrm{x} 100$

Inhibition Percentage (IP)

$\mathrm{IP}=[1-($ allelopathic/control) $] \times 100$

Reduction percentage length $(R P)$

$\mathrm{RP}=[($ control - allelopathic $) /$ control $] \times 100$

Statistical Analysis

Data were analyzed by standard analysis of variance (ANOVA) and student's t-test (before and after treatments) with COSTAT 2.00 statistical analysis software (Zar, 1988). Differences were considered to be significant at $p \leq 0.05$.

\section{Results}

Figures 1 and 2 represent the GP of Panicum turgidum under the effect of cold and hot aqueous extracts of Rosmarinus officinalis and Salvia officinalis respectively. Generally, there is inverse relationship between GP and concentration of the two extracts. With some exceptions, there is gradual decrease in relative germination percentage (Fig. 3) of the recipient species due to the increase in concentration of the extracts.The same trend was shown from the inhibition percentage (Fig. 4).The hot extract of $S$. officinalis shows the highest allelopathic effect on the germination of the seeds of $P$. turgidum. The inhibition percentages are $22.2,22.2,44.4 \& 77.8 \%$ for the concentrations $5,10,20 \& 40 \%$ of the hot water extract of $S$. officinalis respectively.

Reduction in both PL and RL of $P$. turgidum is directly proportional to the increase in concentration of both donor aqueous extracts (Fig. 5). Highest reductions were achieved using $40 \%$ cold and hot aqueous extracts and reached its maximum $(92.21 \%$ and $83.43 \%)$ for radicle and plumule, respectively, for R. officinalis. 

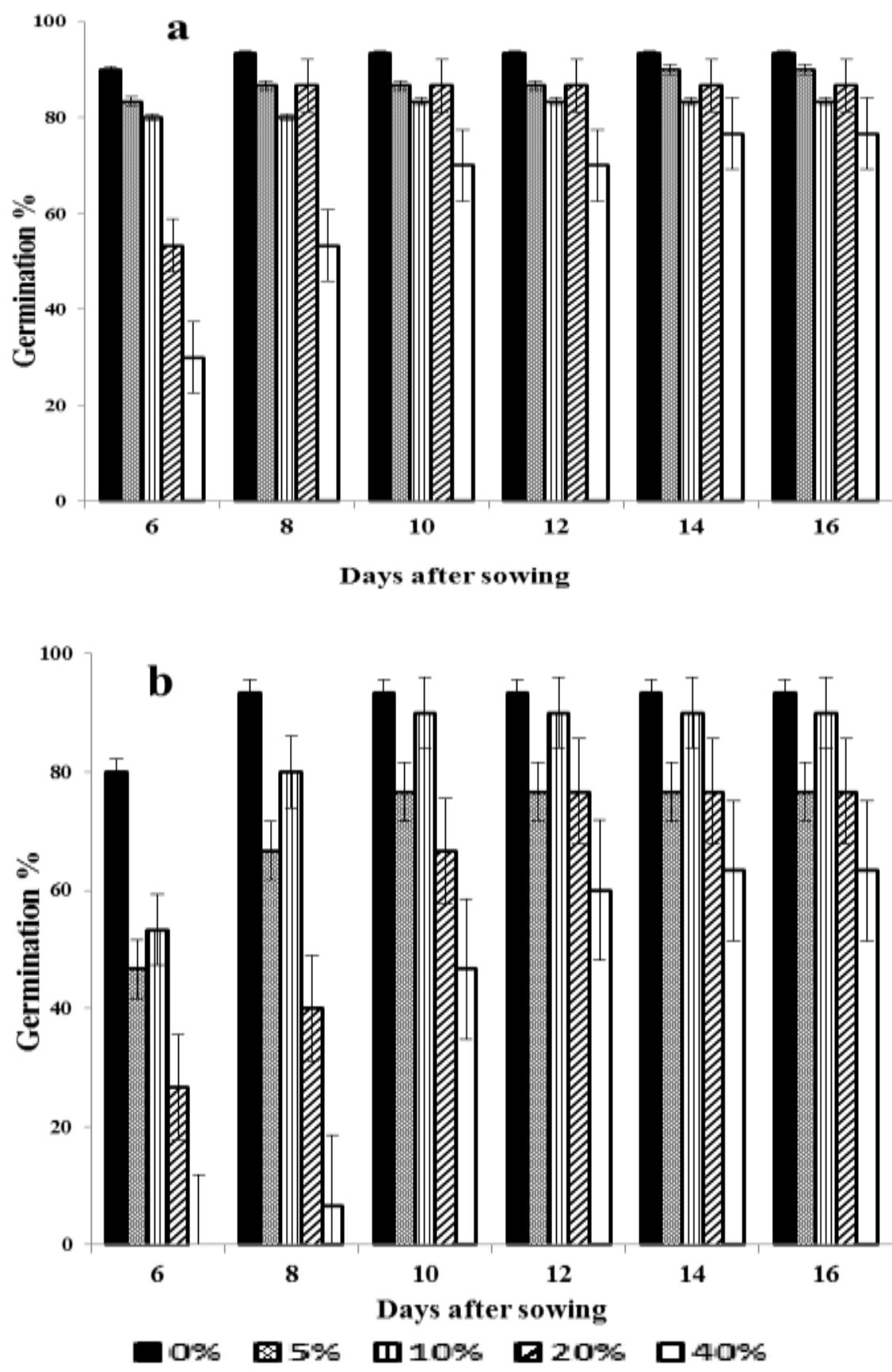

Fig. 1. Germination percentage of Panicum turgidum under the effect of aqueous extracts of Rosmarinus officinalis (a, cold; b, hot). 

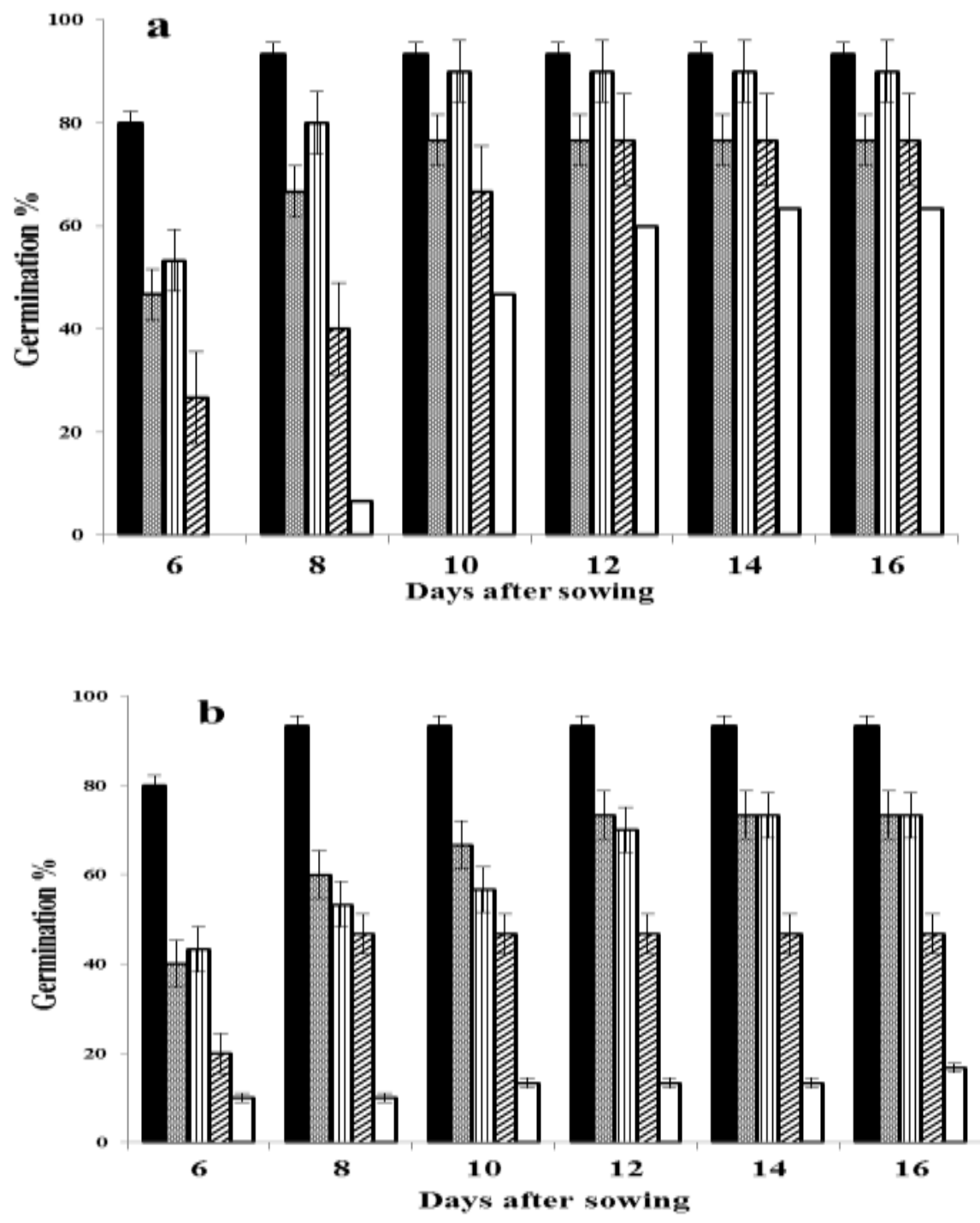

口 $0 \%$ 由 $5 \%$ 四10\% 口20\% 口40\%

Fig. 2. Germination percentage of Panicum turgidum under the effect of aqueous extracts of Salvia officinalis (a, cold; b, hot). 


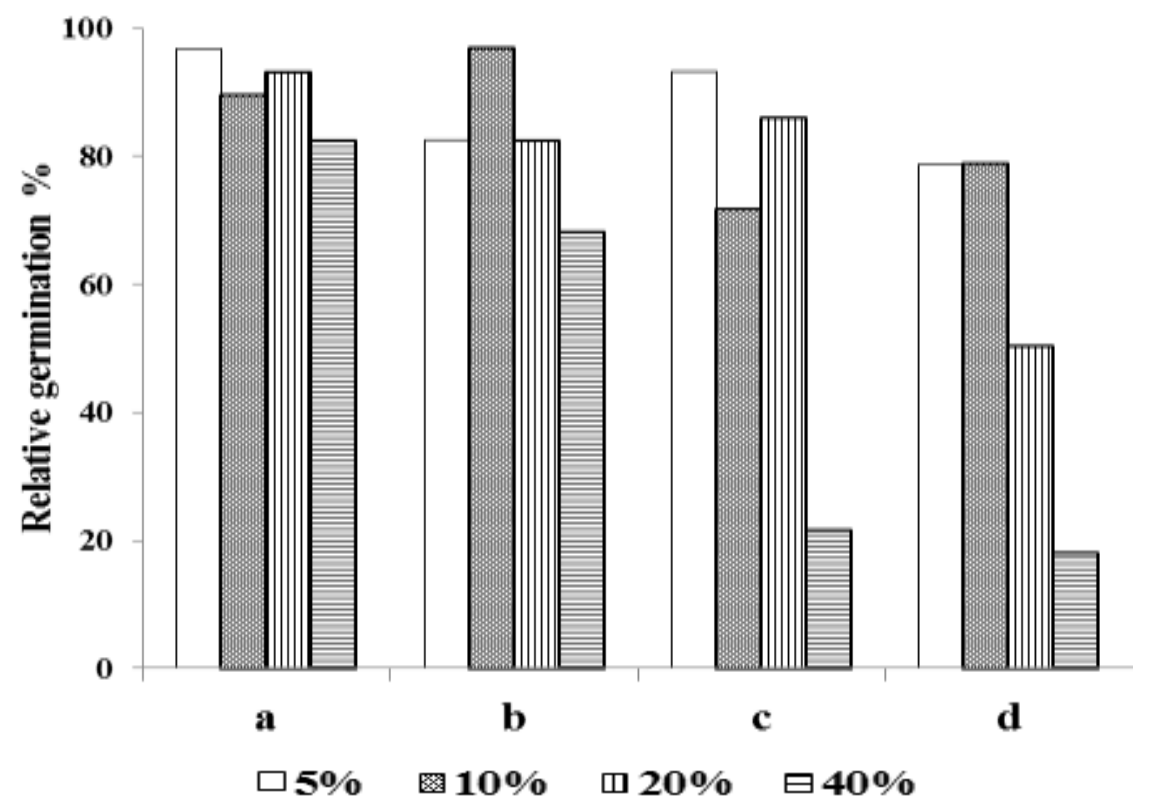

Fig. 3. Relative germination percentage of Panicum turgidum under the effect of aqueous extracts of Rosmarinus officinalis (a, cold; b, hot) and Salvia officinalis (c, cold; d, hot).

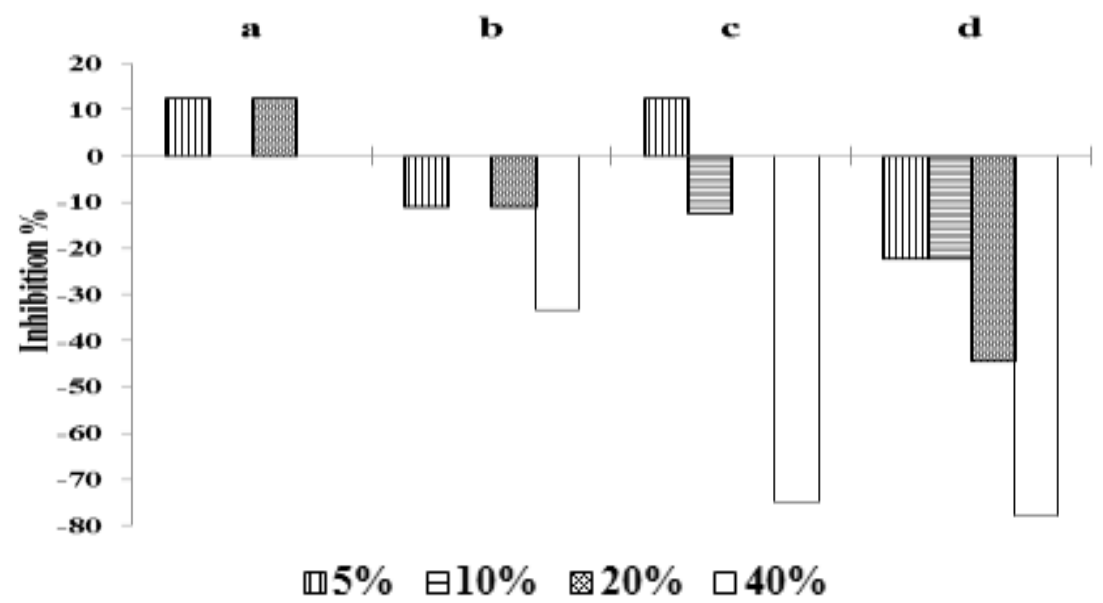

Fig. 4. Inhibition percentage of Panicum turgidum under the effect of aqueous extracts of Rosmarinus officinalis (a, cold; b, hot) and Salvia officinalis (c, cold; d, hot). 

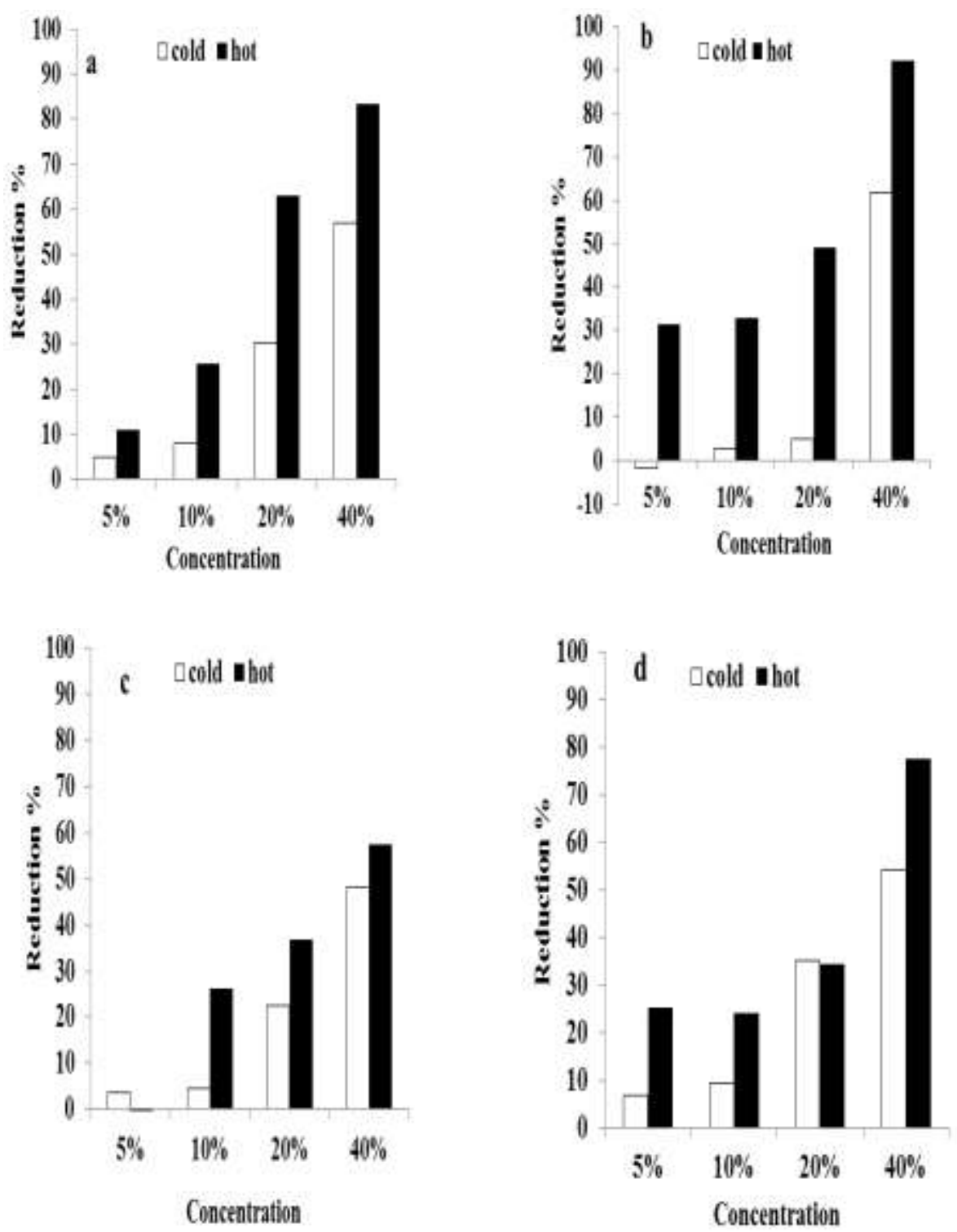

Fig. 5. Reduction percentage of Panicum turgidum under the effect of aqueous extracts of Rosmarinus officinalis (a, plumule; b, radicle) and Salvia officinalis (c, plumule; $d$, radicle). 
Tables 1, 2 and 3 represent comparison between analysis of variance (ANOVA) of the studied treatments according to germination percentage, plumule length and radicle length, respectively. The effect is statistically significant at $\mathrm{p} \leq 0.05$ according to radicle and plumule length for both Rosmarinus officinalis and Salvia officinalis. Meanwhile, it is significant according to germination percentage for Salvia officinalis only. Also, Tables 4, 5 and 6 show repeated paired t-test before and after treatments according to germination percentage, plumule length and radicle length, respectively. The t-test revealed that all concentrations of the two species are significant for germination percentages. Concerning plumule length, most cold and hot concentrations of Rosmarinus officinalis are significant, while most those of Salvia officinalis are non-significant. Reverse trend was noted for radicle length where, most cold and hot concentrations of Salvia officinalis are significant, while most those of Rosmarinus officinalis are non-significant.

TABLE 1. Comparison between the studied treatments according to germination\%.

\begin{tabular}{|c|c|c|c|c|}
\hline \multirow{2}{*}{$\begin{array}{c}\text { Treatment } \\
(\%)\end{array}$} & \multicolumn{4}{|c|}{ Germination \% } \\
\cline { 2 - 5 } & Rosmarinus officinalis & Salvia officinalis \\
\cline { 2 - 5 } & Cold & Hot & Cold & Hot \\
\hline 0 & $79.7 \pm 5.8$ & $93.3 \pm 11.5$ & $83.3 \pm 11.5$ & $93.3 \pm 11.5$ \\
\hline 5 & $90.0 \pm 0.0$ & $76.7 \pm 15.3$ & $86.7 \pm 5.8$ & $73.3 \pm 5.8$ \\
\hline 10 & $83.3 \pm 5.8$ & $90.0 \pm 10.0$ & $66.7 \pm 5.8$ & $73.3 \pm 30.6$ \\
\hline 20 & $86.7 \pm 5.8$ & $76.7 \pm 5.8$ & $80.0 \pm 0.0$ & $46.7 \pm 25.2$ \\
\hline 40 & $76.7 \pm 15.3$ & $63.3 \pm 20.8$ & $20.0 \pm 17.3$ & $16.7 \pm 5.8$ \\
\hline F & 1.600 & 2.321 & $22.733^{*}$ & $7.472^{*}$ \\
\hline $\mathrm{p}$ & 0.249 & 0.128 & $<0.001$ & $0.005^{*}$ \\
\hline LSD at 0.05 & 1.487 & 2.488 & 1.821 & 3.423 \\
\hline
\end{tabular}

TABLE 2. Comparison between the studied treatments according to plumule length.

\begin{tabular}{|c|c|c|c|c|}
\hline \multirow{2}{*}{ Treatment } & \multicolumn{4}{|c|}{ Plumule length (cm) } \\
\cline { 2 - 5 } & \multicolumn{2}{|c|}{ Rosmarinus officinalis } & \multicolumn{2}{c|}{ Salvia officinalis } \\
\cline { 2 - 5 } & Cold & Hot & Cold & Hot \\
\hline $0 \%$ & $1.81 \pm 0.53$ & $1.81 \pm 0.53$ & $2.31 \pm 0.23$ & $2.31 \pm 0.23$ \\
\hline $5 \%$ & $1.72 \pm 0.27$ & $1.61 \pm 0.08$ & $2.22 \pm 0.27$ & $2.36 \pm 0.44$ \\
\hline $10 \%$ & $1.66 \pm 0.14$ & $1.35 \pm 0.39$ & $2.20 \pm 0.45$ & $1.71 \pm 0.52$ \\
\hline $20 \%$ & $1.26 \pm 0.25$ & $0.67 \pm 0.05$ & $1.79 \pm 0.47$ & $1.46 \pm 0.14$ \\
\hline $40 \%$ & $0.78 \pm 0.24$ & $0.30 \pm 0.02$ & $1.20 \pm 0.28$ & $0.98 \pm 0.43$ \\
\hline F & $5.586^{*}$ & $13.898^{*}$ & $3.836^{*}$ & $7.167^{*}$ \\
\hline p & $0.013^{*}$ & $<0.001^{*}$ & $0.044^{*}$ & $0.005^{*}$ \\
\hline LSD 5\% & 0.573 & 0.543 & 0.662 & 0.685 \\
\hline
\end{tabular}

F: F test (ANOVA) *: Statistically significant at $\mathrm{p} \leq 0.05$

Egypt. J. Bot., 56, No. 2 (2016) 
TABLE 3. Comparison between the studied treatments according to radicle length.

\begin{tabular}{|c|c|c|c|c|}
\hline \multirow{2}{*}{ Treatment } & \multicolumn{4}{|c|}{ Radicle length (cm) } \\
\cline { 2 - 5 } & \multicolumn{2}{|c|}{ Rosmarinus officinalis } & Salvia officinalis \\
\cline { 2 - 5 } & Cold & Hot & Cold & Hot \\
\hline $\mathbf{0 \%}$ & $4.45 \pm 0.36$ & $4.45 \pm 0.36$ & $5.39 \pm 0.43$ & $5.39 \pm 0.43$ \\
\hline $\mathbf{5 \%}$ & $4.23 \pm 0.56$ & $3.06 \pm 0.53$ & $3.50 \pm 0.50$ & $4.03 \pm 0.64$ \\
\hline $\mathbf{1 0 \%}$ & $4.33 \pm 0.29$ & $2.99 \pm 0.60$ & $4.88 \pm 0.15$ & $4.09 \pm 1.00$ \\
\hline $\mathbf{2 0 \%}$ & $4.52 \pm 0.44$ & $2.26 \pm 0.85$ & $5.03 \pm 0.89$ & $3.54 \pm 0.60$ \\
\hline $\mathbf{4 0 \%}$ & $1.70 \pm 0.40$ & $0.35 \pm 0.13$ & $2.46 \pm 0.16$ & $1.20 \pm 0.56$ \\
\hline F & $24.962^{*}$ & $22.358^{*}$ & $13.163^{*}$ & $15.574^{*}$ \\
\hline $\mathbf{p}$ & $<0.001^{*}$ & $<0.001^{*}$ & $0.001^{*}$ & $<0.001^{*}$ \\
\hline LSD 5\% & 0.761 & 0.999 & 0.978 & 1.225 \\
\hline
\end{tabular}

F: F test (ANOVA) *: Statistically significant at $\mathrm{p} \leq 0.05$

TABLE 4. Repeated t-test before and after treatments according to germination\%.

\begin{tabular}{|c|c|c|c|c|}
\hline \multirow{2}{*}{$\begin{array}{c}\text { Treatment } \\
(\%)\end{array}$} & \multicolumn{4}{|c|}{ P values } \\
\cline { 2 - 5 } & \multicolumn{2}{|c|}{ Rosmarinus officinalis } & \multicolumn{2}{|c|}{ Salvia officinalis } \\
\cline { 2 - 5 } & Cold & Hot & Cold & Hot \\
\hline $5 \%$ vs Control & $3.062^{*}$ & $3.897^{*}$ & $2.449^{*}$ & $3.266^{*}$ \\
\hline $10 \%$ vs Control & $3.801^{*}$ & $2.449^{*}$ & $3.690^{*}$ & $2.887^{*}$ \\
\hline $20 \%$ vs Control & $3.320^{*}$ & $3.690^{*}$ & $3.897^{*}$ & $4.025^{*}$ \\
\hline $40 \%$ vs Control & $4.382^{*}$ & $4.382^{*}$ & $4.382^{*}$ & $4.382^{*}$ \\
\hline
\end{tabular}

*: Statistically significant at $p \leq 0.05$

TABLE 5. Repeated t-test before and after treatments according to plumule length.

\begin{tabular}{|c|c|c|c|c|}
\hline \multirow{2}{*}{$\begin{array}{c}\text { Treatment } \\
(\%)\end{array}$} & \multicolumn{4}{|c|}{ P values } \\
\cline { 2 - 5 } & \multicolumn{2}{|c|}{ Rosmarinus officinalis } & Salvia officinalis \\
\cline { 2 - 5 } & Cold & Hot & Cold & Hot \\
\hline $5 \%$ vs Control & 0.816 & $2.858^{*}$ & 1.677 & 2.021 \\
\hline $10 \%$ vs Control & $2.887^{*}$ & $3.753^{*}$ & 0.612 & 1.225 \\
\hline $20 \%$ vs Control & $3.578^{*}$ & $3.578^{*}$ & 0.866 & 2.012 \\
\hline 40\% vs Control & $4.017^{*}$ & $4.382^{*}$ & $2.465^{*}$ & $2.739^{*}$ \\
\hline *: Statistically significant at $\mathrm{p} \leq 0.05$ &
\end{tabular}

TABLE 6. Repeated t-test before and after treatments according to radicle length.

\begin{tabular}{|c|c|c|c|c|}
\hline \multirow{2}{*}{$\begin{array}{c}\text { Treatment } \\
(\%)\end{array}$} & \multicolumn{4}{|c|}{ P values } \\
\cline { 2 - 5 } & \multicolumn{2}{|c|}{ Rosmarinus officinalis } & \multicolumn{2}{|c|}{ Salvia officinalis } \\
\cline { 2 - 5 } & Cold & Hot & Cold & Hot \\
\hline $5 \%$ vs Control & 2.008 & 0.816 & $2.683^{*}$ & $3.266^{*}$ \\
\hline $10 \%$ vs Control & 2.021 & 0.722 & $3.175^{*}$ & $3.464^{*}$ \\
\hline $20 \%$ vs Control & 2.449 & $2.571^{*}$ & 0.000 & $3.578^{*}$ \\
\hline $40 \%$ vs Control & 2.012 & $3.469^{*}$ & $3.104^{*}$ & $4.382^{*}$ \\
\hline
\end{tabular}

*: Statistically significant at $\mathrm{p} \leq 0.05$ 


\section{Discussion}

The results indicate that the degree of inhibition on seed germination and growth of the recipient species is largely dependent on the concentration of the extracts of both donor species. These results are in agreement with those of Bajalan et al. (2013 a \& b) who found that Salvia officinalis has strong allopathic effect on germination of barley (Hordeum vulgare) and Purslane (Portulaca oleracea) seeds (2013a) and wheat (Triticum aestivum L.) and velvet flower (Amaranthus retroflexus) seeds (2013b) in such a way that the statistical comparis on indicates the reduction of germination percentage of treated seeds in comparison with control in the level of 5 percent. The results also are in consistence with those of de Almeida et al. (2010) who found that the germination and radicle growth of seeds of Raphanus sativus, Lactuca sativa and Lepidium sativum were affected by twelve essential oils from Mediterranean aromatic plants, of which Salvia officinalis is one of them. Results of Rosmarinus officinalis are also in complete harmony with many previous works. For example, Arouiee et al. (2010) reported that Rosmarinus officinalis leaf extract has allelopathic effect on seed germination and some growth characteristics of Solanum nigrum and Amaranthus retroflexus.

The chemical compositions of Rosmarinus officinalis essential oils have been reported mainly as $\alpha$-pinene, 1.8-cineole and camphor (Azfali et al., 2009). Salvia officinalis essential oil is characterized by high amounts of $\alpha$-thujone, camphor, $\beta$-pinene and $\alpha$-pinene, (Karaaslan and Özguven, 2001). In particular, a high presence of oxygenated monoterpenes is related to a potent phytotoxic activity (de Almeida et al., 2010). Moreover, Vokou et al. (2003) studied the allelopathic activities of 47 monoterpenoids belonging to different chemical groups, estimating their effects on seed germination and subs equent growth of Lactuca sativa seedlings and found that the most active compounds against both processes belonged to the groups of ketones and alcohols, followed by the group of aldehydes and phenols.Our data agree with this findings where significant effects were reported for germination percentage, plumule and radicle lengths but at different levels of activity.

In addition, it is well known that monoterpenes in the essential oils have phytotoxic effects that may cause anatomical and physiological changes in plant seedlings leading to accumulation of lipid globules in the cytoplasm, reduction in some organelles such as mitochondria, possibly due to inhibition of DNA synthesis or disruption of membranes surrounding mitochondria and nuclei (Zunino \& Zygadlo, 2004 and Nishida et al., 2005). However, the specific structural factors, that operate and determine the activity of monoterpenoid and essential oils, remain still obscure (de Almeida et al., 2010).

In conclusion, we have demonstrated that Rosmarinus officinalis and Salvia officinalis have significantly phytotoxic effect on seed germination and growth of Panicum turgidum. Thus, the present study recommends the use of the two donor species for the biocontrol of harmful weeds like Panicum turgidum. At the same

Egypt. J. Bot., 56, No. 2 (2016) 
time the study alerts for the inhibitory effect of these species on the growth of economic plants. Additional work is required to test the efficacy of residues or extracts from these plants on weed control under field conditions and to isolate and identify allelochemicals involved. This information may allow the development of biosynthesized herbicides and other biologically based weed control methods.

Acknowledgment: The authors are very indebted to Dr. Salama El-Darier, professor of plant ecology, Botany and Microbiology Department, Faculty of Science, Alexandria University for his valuable advices during the progress of the work and reviewing the manuscript.

\section{References}

Arouiee, H., Quasemi, S., Azizi, M. and Nematy H. (2010) Allelopathic effects of some medicinal plants extracts on seed germination and growth of common weeds in mashhad area. Proceeding of the 8th international symposium on Biocontrol and Biotechnology. October 4-6, Pattay a, Thailand.

Azfali, D., Jamshidi, R. and Azfali, Z. (2009) Chemical composition of Hydrodistillation essential oil of Rosemary in different origins in Iran and comparison with other countries, American-Eurasian. J. Agric. Environ. Sci., 5, 78-83.

Bajalan, I., Zand, M. and Rezaee, S. (2013a) Allelopathic effects of aqueous extract from Salvia officinalis L. on seed germination of Barley and Purslane. Int. J. Agric. Cr. Sci., 5(7), 802-805.

Bajalan, I., Oregano, K.E., Moezi, A. and Gholami, A. (2013b) Allelopathic effects of aqueous extract from Salvia officinalis L. on seed germination of wheat and velvet flower. Tech. J. Eng. Appl. Sci., 3(6), 485-488.

de Albuquerque, M.B., dos Santos, R.C., Lima, L.M., Filho, P.D., Nogueira, R.J., da C^amara C.A. and Ramos, A.D. (2011) Allelopathy, an alternative tool to improve cropping systems. A review. Agron. Sust. Dev., 31, 379-395.

de Almeida, L.F., Frei, F., Mancini E., De Martino, L. and De Feo, V. (2010) Phy totoxic activities of mediterranean essential oils. Molec., 15, 4309-4323.

Derwich, E., Benziane, Z. and Chabir, R. (2011) Aromatic and medicinal plants of Morocco: Chemical composition of essential oils of Rosmarinus officinalis and Juniperus Phoenicea. Int. J. Appl. Biol. Pharm. Technol., 2(1), 145-153.

Gholami, B.A., Faravani, M. and Kashki, M.T. (2011) Allelopathic effects of aqueous extract from Artemisia hopetdaghensis and Saturej hortensison growth and seed germination of weeds. J. appl. environ. boil. sci., 1(9), 283-290.

Inderjit, K. and Keating, K.I. (1999) Allelopathy: principles, procedures, processes, and promises for biological control. Adv. Agron., 67, 141-231.

Egypt. J. Bot., 56, No. 2 (2016-) 
Ismail, A.M.A. and Seed, M.T. (1983) Some aspects of autecology of Panicum turgidum Forssk. Qat. Univ. Scient. Bull., 3, 91-101.

Isman, M.B. (2000) Plant essential oils for pest and disease management. Cr. Prot., 19, 603-608.

Karaaslan, D. and Özguven, M. (2001) Determination of qualitative and quantitative features of sage (Salvia officinalis L.) essential oils. Pakistan Journal of Biological Sciences, 4(1): 41-43.

Migahid, A.M. and El Shourbagy, M.N. (1961) The ecological amplitude of the desert grass Panicum turgidum Forssk. 1. Comparison of climatic conditions at Ras ElHikma, Fuka and Almaza. Bull. Inst. Des., 8, 1-20.

Nishid, N., Tamotsu, S., Nagata, N., Saito, C. and Sakai, A. (2005) Allelopathic effects of volatile monoterpenoids produced by Salvia leucophylla: inhibition of cell proliferation and DNA synthesis in the root apical meristem of Brassica campestris seedlings. J. Chem. Ecol., 31, 1187-1203.

Omid-Beigi, R. (2009) "Production and processing of medicinal plants", Vol. 2, Behnashr Publisher, Mashhad, Iran.

Ozcan, M.M. and Chalchat, J. (2008) Chemical composition and antifungal activity of rosemary (Rosmarinus officinalis L) oil from Turkey. Int. J. Food Sci. Nutr., 59(7-8), 691-698.

Papachristos, D.P. and Stampoulos, D.C. (2004) Fumigant toxicity of three essential oils on the eggs of Acanthoscelides obtectus (Say) (Coleoptera: Bruchidae). J. Stor. Prod. Res., 40, 517-525.

Pozzatti, P., Alves S cheid, L., Borba S pader, T., LindeAtayde, M., MoraisSanturio, J. and Hartz Alves, S. (2008) In vitro activity of essential oils extracted from plants used as spices against fluconazole-resistant and fluconazole-susceptible Candida spp. Canad. J. Microbiol., 54 (11), 950-956.

Takaki, I., Bersani-Amado, L.E., Vendruscolo, A., Sartoretto, S.M., Diniz, S.P., Bersani-Amado, C.A. and Cuman, R.K. (2008) Anti-Inflammatory and Antinociceptive effects of Rosmarinus officinalis L. Essential oil in experimental animal models. J. Med. Food., 11 (4), 741-746.

VanGessel, M. (1995) "Texas Panicum Control in Field Crops and Commercial Vegetables", Cooperative extension education in agriculture and home economics, University of Delaware, Delaware State University and the United States Department of Agriculture cooperating.

Vokou, D., Douvli, P., Blionis, G.J. and Halley, J.M. (2003) Effects of monoterpenoids, acting alone or in pairs, on seed germination and subsequent seedling growth. $J$. Chem. Ecol., 29, 2281-2301.

Wang, W., Wu, N., Zu, Y. and Fu, Y. (2008) Antioxidative activity of Rosmarinus officinalis L. essential oil compared to its main components. Food Chem., 108, 10191022.

Egypt. J. Bot., 56, No. 2 (2016) 
Zar, J.H. (1988) "Biostatistical analysis", $4^{\text {th }}$ ed. Prentice Hall.

Zunino, M.P. and Zygadlo, J.A. (2004) Effect of monoterpenes on lipid oxidation in maize. Planta, 219, 303-309.

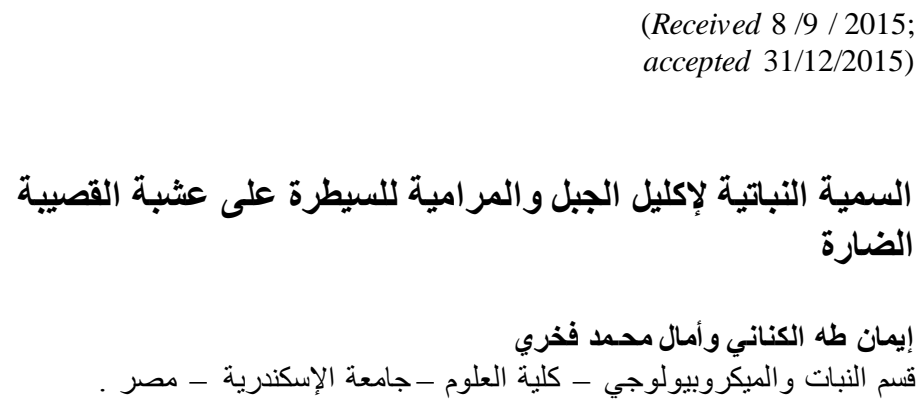

التباعد التضادى الكيمبائي هو آلية تداخلية تطلق من خلالها النباتات بعض المو التواد

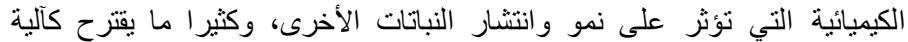

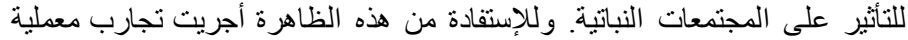

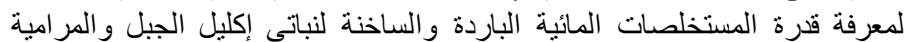

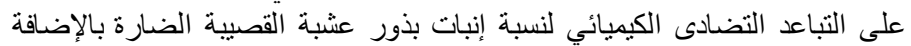

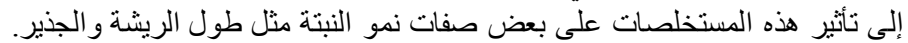

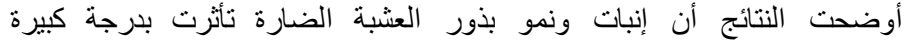

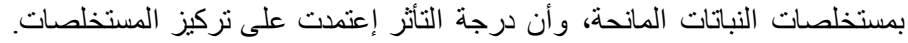

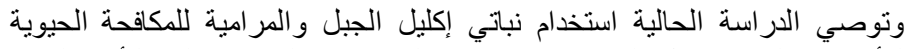

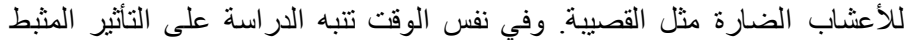

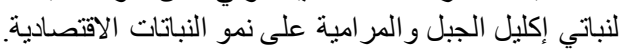

